\title{
Hardware Implementation of Electronic Railway Ticket
}

\author{
Shesha H Shukla, Ankit Shah \\ (Department of Electronics and Telecommunication, Dwarkadas J. Sanghvi College of Engineering/ Mumbai \\ University, India) \\ ${ }^{2}$ (Department of Electronics and Telecommunication, Dwarkadas J. Sanghvi College of Engineering/ Mumbai \\ University, India)
}

\begin{abstract}
We have designed a rechargeable electronic ticket using a microcontroller and an Xbee module which is a W.S.N i.e. a wireless sensor network. All stations are assumed to have a sensor which senses the commuters' ticket and shows a green light if there is enough balance in the ticket and red otherwise. The balance in the ticket gets adjusted in the database of the particular commuter as a unique ID is assigned to each and every commuter. The proposed system thus aims at saving the commuters' valuable time and also saves the environment by avoiding wastage of paper.
\end{abstract}

Keywords: Database, microcontroller, receiver, rechargeable, transmitter, wireless sensor module

\section{INTRODUCTION}

Railways are the most popular mode of travel in India. It is relatively cheap and so is affordable to most of the citizens. This paper aims at making travel easier for frequent commuters. Here we have discussed the hardware implementation of an electronic railway ticket which is made using ATmega8 microcontrollers and wireless sensor modules.

\section{WORKING}

The proposed system has a rechargeable $9 \mathrm{~V}$ battery which is made of NiMH. The battery is connected to the 7805 Regulator which regulates the voltage to $5 \mathrm{~V}$ as the ATMega 8 microcontroller used in this system works on $5 \mathrm{~V}$. The battery is rechargeable which allows the system to charge the ticket. The system uses microcontroller ATMega8 which is a 28 pin microcontroller. Its pin no. 7 is connected to Vcc and Ground is connected to pin no. 8 . Pin no. 1 is pulled up via a $10 \mathrm{~K}$ resistor for reset circuitry. The system uses a crystal of $16 \mathrm{MHz}$ frequency which is connected between pin nos. 9 and 10. Pin no. 2 and 3 of the IC are used as transmitter and receiver. These are connected to the Xbee module which is a programmable wireless module. The Xbee module can form a W.S.N i.e. Wireless Sensor Network. Wireless sensor networks have recently come into prominence because they hold the potential to revolutionize many segments of our economy and life, from environmental monitoring and conservation, to manufacturing and business asset management, to automation in the transportation and health-care industries.[1] Xbee has a capacity of up to $100 \mathrm{~m}$ wireless transreception. A unique ID will be set inside the microcontroller which will be continuously transmitted via the Xbee module via the ticket. Once the receiver module at the station receives the ID there will be a bicoloured LED (Green and Red) which shows if the ticket has enough balance. If the system has sufficient balance the LED will glow Green and if the balance is insufficient then the LED will turn Red. In case a Ticket Checker catches the person carrying the E-Ticket, the user has to show that the LED has turned Green which would mean that the ticket is valid. On the receiver end this system will be having an Xbee module and it's USB Explorer. The XBee product family is a seriesof modular products that make deploying wireless technology easy and costeffective.[2] On the receiving station server the ID we had sent by the microcontroller will be received by the USB Explorer. Once the ID is received at the station, the computer system denotes that the person has arrived at that particular station. Software is written in MATLAB which has a database keeping record of the ticket and its balance in .MAT file format. Now this Software will search for the ID and reduce the corresponding amount from the database. The system has two receivers on each station, one at the entrance and another at the exit. If the person just enters and leaves the station, a station ticket amount will be charged or if he travels to some other station the corresponding balance will be deducted. The Block Diagram and flowcharts are shown below. 


\section{FIGURES AND TABLES}

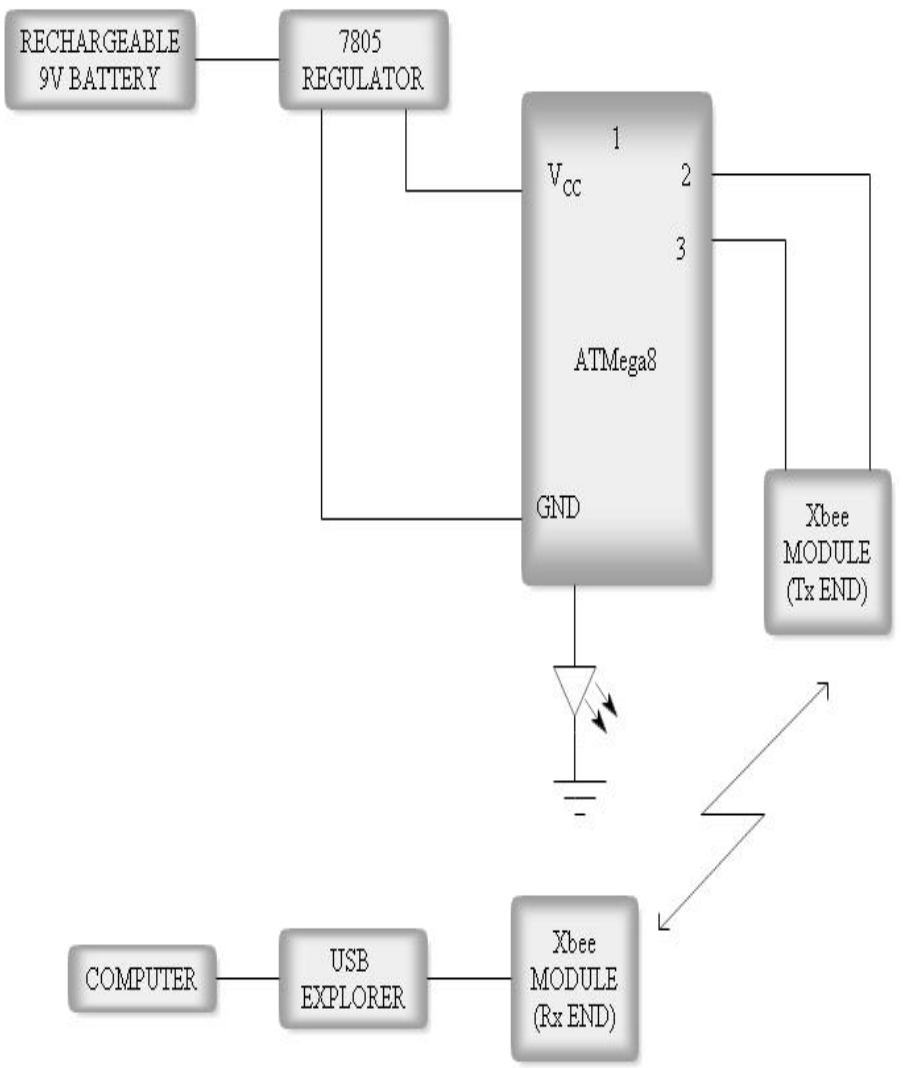

Fig 1: Block Diagram

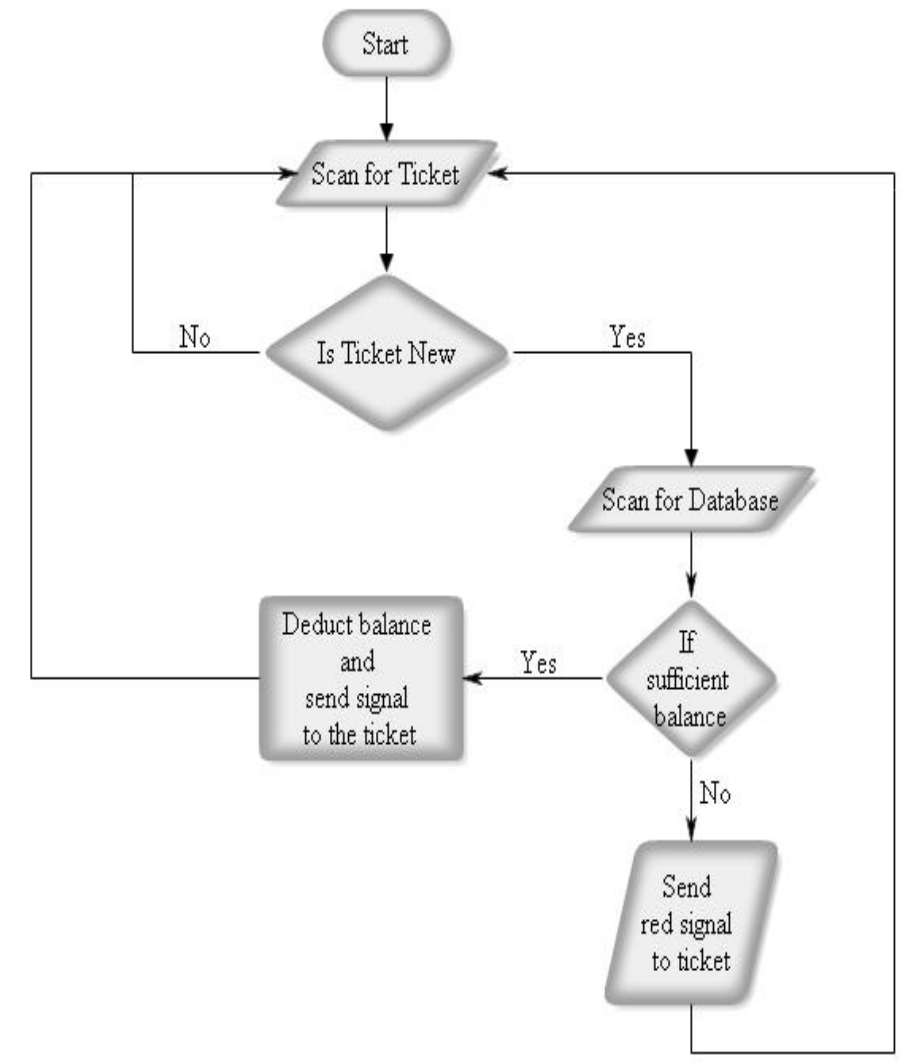

Stop

Fig 2: Flow Chart for Station Server 


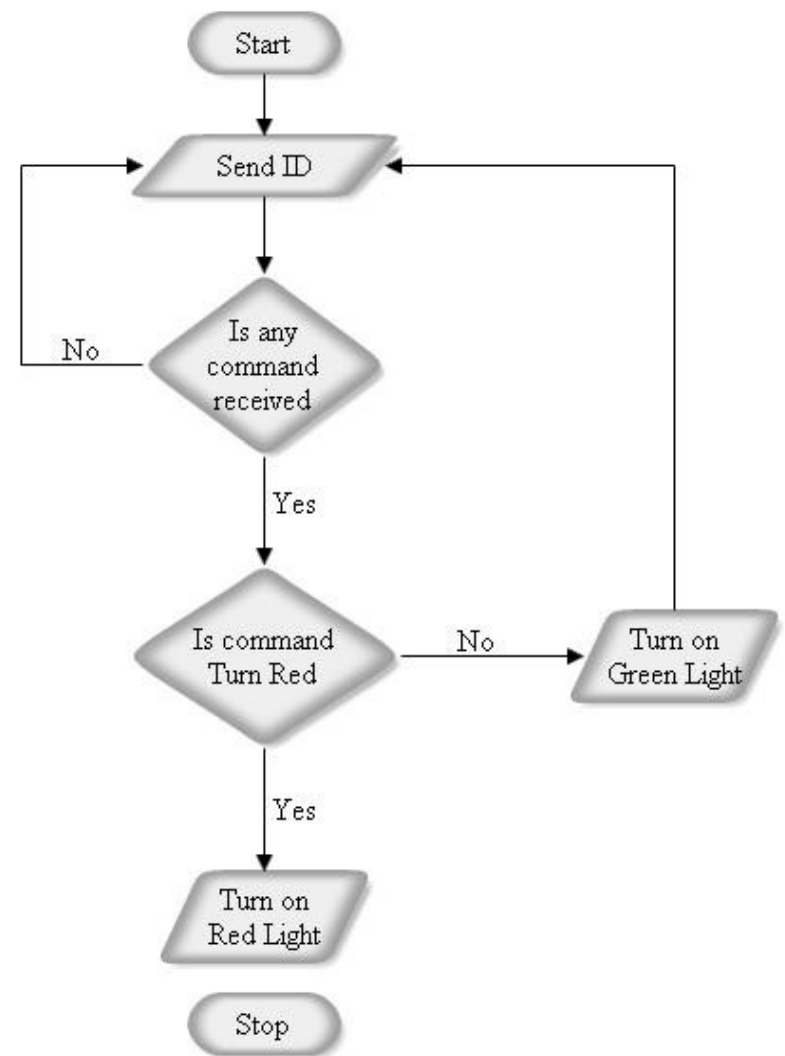

Fig 3: Flow Chart for the Electronic Ticket

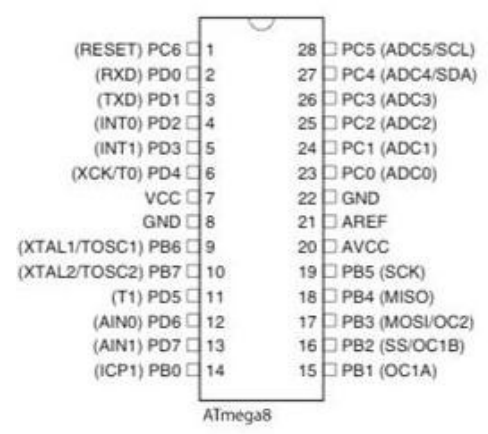

Fig 4: Pin Diagram of ATMega8 Microcontroller

\section{CONCLUSION}

The system most importantly aims at saving time of the commuters. Since the ticket we have designed is rechargeable in sense of battery as well as balance it becomes very easy for the traveler in case the person is running late or even otherwise. This system is thus designed to make travel more convenient for the citizens as they will no longer have to waste time by standing in long queues. It will also avoid wastage of paper and thus help in saving our environment. It can even be implemented in the existing railway system without much modification.

\section{Acknowledgements}

We would like to thank the honorable Principal Dr. Hari Vasudevan of D.J.Sanghvi College of Engineering and Head of Department of Electronics and Telecommunication, Dr. Amit Deshmukh for encouraging us and giving us immense guidance. We would also like to thank SVKM (Shri Vile Parle Kelavani Mandal) for supporting us in such co-curricular activities.

\section{REFERENCES}

[1] Wireless Sensor Networks: An Information Processing Approach, by Feng Zhao and Leonidas Guibas, pg xiii

[2] http://www.digi.com/xbee

[3] http://www.atmel.com/images/doc2486.pdf 